\title{
A New Skin Friction Meter of Floating-Element Type and the Measurements of Local Shear Stress
}

\author{
Takio Hotta*, Member
}

\begin{abstract}
Summary
This paper presents a new device for the measurement of local shear stress, based on floatingelement technique, on a three-dimensional body surface submerged in water. Improvements are made for the new meter to eliminate the flow passing through the gap around its element completely, to reduce the force due to the pressure acting on the side of the floating element, and to satisfy approximately the no-slip condition for the flow at the gap. The measurements of local shear stress are carried out on the surfaces of a flat plate, a two-dimensional body and a streamlined body. The experimental results agree very well with the calculated ones, which shows that the device determines the wall shear stress of a submerged three-dimensional body accurately.
\end{abstract}

\section{Introduction}

The characteristics of the incompressible turbulent boundary layer flow on a ship-like body are calculated by numerical procedure recently. The calculation is based on a three-dimensional boundary layer theory which requires some assumptions for the flow. They are the power law for the velocity profile in the layer and the application of the formula for local wall shear stress on a two-dimensional surface to a three-dimensional one. The correct value of the shear stress has not been obtained either by a numerical procedure or by an experimental one. If the measurement of the shear stress becomes possible, it should give considerable contribution to the development of the three-dimensional boundary layer theory.

For the determination of the wall shear stress, a direct method and an indirect one had been used. The latter method is based on the measurement of the boundary layer velocity profile or of the rate of heat transfer from a hot film to the water in the boundary layer. However, the method has not necessarily given a satisfactory result.

In the present paper, a direct method is used. The local wall shear stress is measured directly by a friction measurement device of floating-element type. The device has a circular floating element which is mounted flush with the surrounding body surface and separated from the surface by a small gap. The shear stress acting on the floating element is evaluated by the device.

Using this type of friction meter, S. Dhawan ${ }^{1)}$ and D. W. Smith \& J. H. Walker ${ }^{2}$ measured the local shear stress on a flat plate without pressure gradient. The local shear stress on a flat plate with pressure gradient was measured by K. C. Brown \& P. N. Joubert ${ }^{3)}$ by means of a meter similar to the meter used in References 1) and 2). The determination of local shear stress on a ship model was carried out by J. N. Prischemihin \& A. P. Poostoshny) using an instrument whose element was one end surface of a flexible cylinder. Their result agreed reasonably well at high Reynolds number but did not agreed well at low Reynolds number.

* Department of Naval Architecture, Faculty of Engineering, Hiroshima University, Hiroshima 
Difficulties in application of the floating-element technique to the surface with pressure gradient. were pointed out by K. C. Brown \& P. N. Joubert and B. N. Steele \& G. B. Pearce ${ }^{5)}$. Due to the existence of a gap around the floating element, the element receives some forces together with the shear stress by the following three causes. 1) The pressure gradient on the element gives rise the flow from the gap, which is called as the gap flow. 2) The pressure force acts on the vertical side of the floating element. 3) The flow on the gap does not satisfy the no-slip condition, i.e., the velocity of viscous flow must be zero at a solid surface. It is attempted by the author to remove: these difficulties of the floating-element technique. For the cause 1), the space just behind the gap is divided into several cells, which are open to the gap. The pressure in each cell balances with that on the boundary layer outside the cell; i.e., no fluid passes through the backside of the circular floating element. For the cause 2), the side of the element is made to be as thin as possible; thus, the force due to the pressure working on the side becomes negligibly small. For the cause 3), the gap is designed to have such a small dimension that the flow at the gap satisfies the no-slip condition approximately. Furthermore, in order to fit the floating element on a three-dimensional surface, the element diameter is made to be very small compared with the principal radii of curvature of the surface. As described above, the new friction meter has an advantage over the conventional meters toward the secondary effects.

In this paper, a new device, applicable to a three-dimensional surface for the measurement of the local wall shear stress, is described. Its structure, measurement technique and the results are also described. Using this meter, measurements were made for cases of a flat plate and a two-dimensional body. These results are compared with the values of the shear stresses measured by other investigators ${ }^{1,2,3)}$ and calculated by the author.

The agreement between these results may be considered as an indication that the present method is an effective means for the determination of the local shear stress. Then, measurements of the shear stress on the three-dimensional body, submerged in water, are made at six points on the body. Calculation of the local shear stress is carried out by numerical method, based on the threedimensional boundary layer theory, by the author ${ }^{6}$. Measured results agree very well with the calculated results. From this agreement, it is seen that the new friction meter determines the local shear stress on the three-dimensional surface without the secondary effects due to the gap.

The experiment is carried out in a circulating water channel, in the range $6 \times 10^{5}$ to $12 \times 10^{5}$ of the Reynolds number based on the body length. The determination of the local wall shear stress is obtained by measuring the boundary layer velocity profile. The shear stress on the flat plate and those on the two- and three-dimensional body surfaces are evaluated by Clauser's method ${ }^{7}$ and Ludwieg \& Tillmann's formula ${ }^{8)}$ respectively at the Reynolds number $10^{6}$. It is shown that these results agree very well with those of the direct measurements.

\section{Friction Meter}

The friction meter has a cylindrical shape of $50 \mathrm{~mm}$ in length and $30 \mathrm{~mm}$ in diameter, as shown in Fig. 1. The main parts of the meter are, 1) a floating element and its suspension system, 2) cells behind the floating element, 3) lamps and photo-transistors, 4) electromagnetic coils and a permanent magnet and 5) ducts.

The floating element 1 ) is a disk of $14 \mathrm{~mm}$ in diameter. This is connected with one end of a rod whose other end is suspended by tensioned stainless wires of $0.1 \mathrm{~mm}$ in diameter in the direction perpendicular to the rod, as shown in Fig. 1. The element and the rod can be moved around the line connecting the upper and lower ends of the wires. These ends are fixed to an inner cylinder 
which is installed inside of an outer cylinder coaxially. By sliding the inner cylinder while the outer cylinder is held stationary, the gap width is adjusted. The cells behind the floating element 2) divide the space behind the gap into ten small spaces and each space is open to the gap. The back surface of the floating element closes to the cells by the clearance of $0.03 \mathrm{~mm}$. A couple of lamps and phototransistors 3) are used to detect the motion of the magnet similar to that of the floating element. According to the amount of the displacement of the magnet, the phototransistors receive various amount of light from the lamps. The motion of the floating element may be observed as the motion of indicator of the picoammeter associated with the phototransistors as shown in Fig. 2. The electromagnetic coils 4) supply the magnet with force by which the shear stress acting on the element is balanced. The intensity of magnetic field is so weak that this is not affected by the iron near the friction meter. When submerged in water, by applying the suction on one end of the duct 5), the air in the cells and in the space inside the friction meter is removed. At the back side of the meter, these ducts are joined with vinyl tubes which are led to a suction pump.

For the measurement of the skin friction based on the floating-element principle, as described above, three difficulties take place. They are the gap flow, the pressure force acting on the side of the floating element, and the no-slip condition for the flow at the gap. Improvements for the friction meter are made in order to reduce these difficulties.

The effect of the gap flow is reduced by constructing the device so that the gap around the element becomes as small as $0.05 \mathrm{~mm}$. It is shown by Brown \& Joubert ${ }^{3)}$ that the gap width is proportional to the magnitude of the secondary force acting on the element. The present gap width is smaller than that of $0.1 \mathrm{~mm}$ of Dhawan's device ${ }^{1)}$ and that of $0.076 \mathrm{~mm}$ of Brown \& Joubert's. Furthermore, the clearance between the back surface of the element and the cells is made to be $0.03 \mathrm{~mm}$. The clearance is small enough to prevent the flow of viscous fluid through it even when the pressure gradient exists there. The pressure in each cell, therefore, is balanced by the pressure in the boundary layer flow just outside the cell when one end of the duct, which is connected to the cell, is closed.

Since the fluid in the backsides of the floating element and the gap is stationary, there exists no flow through the gap. This prevents occurrence of a secondary force due to the momentum exchange between the gap flow and the boundary layer flow. Another secondary force is a pressure force acting on the side of the element by penetration of the free-stream pressure into the gap. Magnitude of this force is proportional to the thickness of the element as shown by Brown \& Joubert. In this case the thickness is $0.1 \mathrm{~mm}$. The secondary effect due to the thickness may be evaluated by using the pressure gradient at the position where the element locates. For the three-dimensional body, the rate of the pressure force to the total force acting on the element is estimated to be less than $1.7 \%$. This may be regarded as a negligibly small value.

Since the floating element has a flat surface, i.e., a surface without curvature, when it is installed on a surface of a three-dimensional body, discontinuity takes place along the body surface. The degree of the discontinuity can be represented by two quantities. One is a distance between the floating element and the original body surface, and the other is an angle formed by the tangential line, drawn on the body surface at the point of the discontinuity, and the surface of the floating element. For the three-dimensional body used in the present investigation, the former is at most $0.05 \mathrm{~mm}$ and the latter 0.5 degree. These values are small enough to consider that the effect of the discontinuity due to installation of the floating element is negligibly small.

The no-slip condition for the fluid at the gap can not be satisfied for the friction meter by means of the floating-element technique. However, it is considered that the small dimension of the gap width of $0.05 \mathrm{~mm}$ satisfies the no-slip condition approximately. 


\section{Calibration}

Calibration of the friction meter is made by using a balance which is made up of a horizontal bar and a vertical lever as shown in Fig. 3. The lower end of the lever is connected to a flexible wire of $0.1 \mathrm{~mm}$ in diameter whose axis is in the horizontal direction. The wire, shown as heat wire in the figure, contacts with the floating element at its center where small amount of paraffine is deposited. By applying electrical current to the wire for a short time the wire is heated. The paraffine is melted, and then the wire contacts with the floating element. On one end of the horizontal bar a weight is placed and then the weight is balanced by the electromagnetic force of the friction meter. Equilibrium of the balance is found from the position of an indication needle of the picoammeter associated with the phototransistors. The relation between the force imposed on the floating element from the balance and the current supplied to the field coils is represented by a straight line as shown in Fig. 3.

\section{Experiment*}

The measurement of the local wall shear stress is made for a flat plate, a two-dimensional body and a three-dimensional body. The flat plate and the two-dimensional body are chosen so that the accuracy of the meter can be evaluated by comparing with the results of known values. Principal dimensions of these three kinds of bodies are given in Table 1 and their profiles are shown in Figs. 4,5 and 6 respectively. On each body surface, cylindrical studs are placed at locations $2.5 \%$ and $5 \%$ of the body length downstream from the leading edge. Measurements are carried out in a circulating water channel whose test section is $3 \mathrm{~m}$ long, $1.2 \mathrm{~m}$ wide and $0.82 \mathrm{~m}$ deep.

The measurement on the flat plate is made at the location $s / S=0.5$, where $s$ denotes a length measured along the streamline on the body surface from the leading edge to the measuring point and $S$ its total length on the surface. Measurements on the two-dimensional body are made at locations $s / S=0.3,0.5$ and 0.7. For the three-dimensional body the measurements are made on two streamlines, that is, streamline $A$ and streamline $B$ on the surface as shown in Fig. 6. On each streamline, measurements are made at locations $s / S=0.3,0.5$ and 0.7 . The profiles of these two streamlines are presented in the cartesian coordinate in the author's paper ${ }^{6}$.

The friction meter is installed to the body which is placed on the horizontal plane. The floating element of the meter is flushed with the surrounding surface. After the body is submerged in water, air inside the friction meter is removed through the ducts. Water in the ducts is held to be stationary by closing one ends of these tubes. In the steady flow of water, the local wall shear stress acting on the floating element of the friction meter is balanced by the electromagnetic force. The shear stress is determined from the current supplied to the field coils. Speed of water used for the experiment ranges from $0.4 \mathrm{~m} / \mathrm{sec}$ to $0.85 \mathrm{~m} / \mathrm{sec}$, and Reynolds number based on the uniform flow velocity and body length, $U L / \nu$, from $6 \times 10^{5}$ to $12 \times 10^{5}$. In the range tested, magnitude of the force acting on the element is measured in the range from $7 \mathrm{mg}$ to $30 \mathrm{mg}$.

\section{Results}

The results of direct measurements of the local shear stress on the flat plate, the two- and threedimensional bodies are shown in Figs. 4, 5 and 6 respectively. In these figures ordinate represents the local skin friction coefficient $\tau_{w} / \rho U_{0}^{2}$ or $\tau_{w} / \rho U^{2}$, where $\tau_{w}$ is local wall shear stress tangential to the streamline, $\rho$ fluid density, $U_{0}$ uniform flow velocity and $U$ free stream velocity just outside the boundary layer. The abscissa represents Reynolds number $U_{0} s / \nu$ or $U_{0} L / \nu$, where $s$ is streamline length up to the measuring position, $L$ body length and $\nu$ kinematic viscosity. 
In Fig. 4 the local skin friction coefficient on the flat plate is shown in comparison with the results obtained by the semi-empirical formula ${ }^{9)} \tau_{w} / \rho U_{0}^{2}=0.0296\left(U_{0} s / \nu\right)^{-1 / 5}$, Dhawan's experimental result and the result obtained by Clauser's method. The value by the last method is determined by the measurement of the boundary layer velocity profile distribution. The results of Smith \& Walker and Brown \& Joubert are also shown. Their results, which were obtained in the higher range of Reynolds number, are reduced to those in the range of Reynolds number used in the present experiment by applying an interpolation method. The results obtained by the present friction meter are in comparatively fair agreement with other experimental results.

In Fig. 5 the local skin friction coefficients on the two-dimensional body are shown for three measuring points. These are compared with the results calculated by the author and with the experimental results obtained by the application of the Ludwieg \& Tillmann formula. The formula is represented by $\tau_{w / \rho} U^{2}=0.123 \times 10^{-0.678 H}(U \theta / \nu)^{-0.268}$, where $H$ is a shape parameter and $\theta$ a momentum thickness. The results of the direct measurement agree well with both results. This shows that the friction meter can measure accurately the local shear stress for a two-dimensional surface with pressure gradient and curvature.

In Fig. 6 the local skin friction coefficients on the three-dimensional body are shown for three measuring points on each of the streamlines A and B. Experimental results evaluated by the Ludwieg \& Tillmann formula and the results calculated by the author are also presented. The calculation procedure is according to Cumpsty \& Head's method ${ }^{10)}$ for a three-dimensional turbulent boundary layer. The friction coefficients are determined from the boundary layer calculation based on streamline coordinates. The method of determining these streamline coordinates has been shown in the author's paper ${ }^{11)}$. The results of the direct measurement are in very good agreement with those of the calculation and those by the Ludwieg \& Tillmann formula. From the agreement it is concluded that the new friction meter of floating-element type can measure accurately the local wall shear stress on a three-dimensional body surface submerged in water.

\section{Conclusion}

A new friction meter based on a floating-element technique is developed to measure the local shear stress on a three-dimensional surface submerged in water. The present meter is constructed so that the secondary force effect is eliminated as much as possible. Direct shear stress measurements by the meter are carried out for a flat plate, -two- and three-dimensional bodies in the range of Reynolds number from $6 \times 10^{5}$ to $12 \times 10^{5}$. These experimental results agree very well with the results obtained by the calculation and those obtained by the velocity measurements in the boundary layer. Therefore it is concluded that the new friction meter can measure accurately the local shear stresses not only on a flat plate and a two-dimensional body but also on a three-dimensional body.

\section{Acknowledgement}

The author wishes to express his sincere gratitude to Prof. S. Hatano of Hiroshima University for his guidance to the present work. He would also like to express his appreciation to Messrs. Y. Enami of Sasebo Heavy Industries, Ltd. and T. Yoneda of Tsuneishi Ship building Co., Ltd. for their help with the experiments.

\section{References}

1) S. Dhawan: Direct Measurements of Skin Friction, NACA T. Rep. 1121 (1953).

2) D. W. Smith and J. H. Walker: Skin-Friction Measurements in Incompressible Flow, NASA T. Rep. R-26 (1959). 
3) K. C. Brown and P. N. Joubert: The Measurement of Skin Friction in Turbulent Boundary Layers with Adverse Pressure Gradients, Jour. Fluid Mech., Vol. 35 (1969).

4) J. N. Prischemihin and F. Poostoshny: Investigation of Turbulence Stimulation in the Boundary Layer of Ship Models Tested in Towing Tanks, 9th ITTC Conference (1960).

5) B. N. Steele and G. B. Pearce: Experimental Determination of the Distribution of Skin Friction on a Model of a High Speed Liner, Quart. Trans. Roy. Instn. Nav. Arch. (Jan. 1968).

6) T. Hotta: On the Difference between Developments of Two- and Three-Dimensional Turbulent Boundary Layers, Jour. Soc. Nav. Arch. Japan, Vol. 136 (1974).

7) F. H. Clauser: Turbulent Boundary Layers in Adverse Pressure Gradients, Jour. Aeronaut. Sci. Vol. 21 (1954).

8) H. Ludwieg and W. Tillmann: Untersuchungen über die Wandschubspannung in Turbulente Reibungsschichten, Ing. Arch., Bd. 17 (1949).

9) H. Schlichting: Boundary-Layer Theory (McGraw-Hill, New York, 1968) 6th ed., p. 600.

10) N. A. Cumpsty and M. R. Head: The Calculation of Three-Dimensional Turbulent Boundary Layers, Part 1, Aeronaut. Quart., (Feb. 1967).

11) T. Hotta: A Method for Calculating Three-Dimensional Turbulent Boundary Layer by Using Streamline Co-ordinates, Japan. Jour. Appl. Phys., No. 6 (1973).

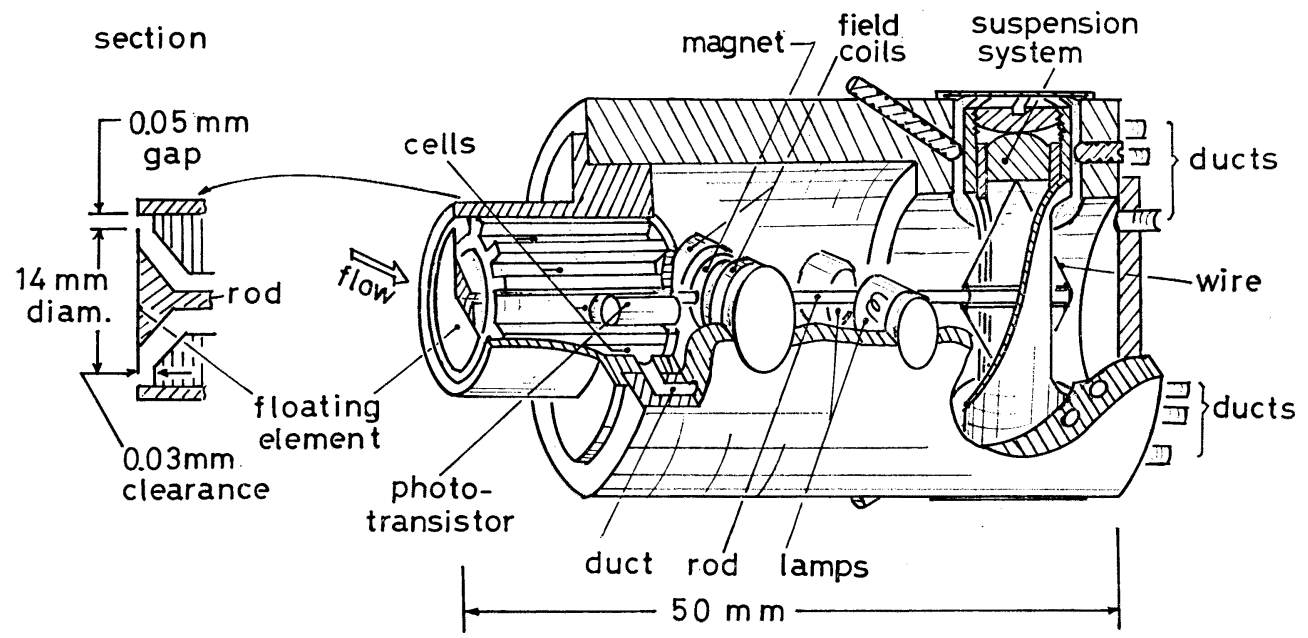

Fig. 1 Arrangement of the skin friction meter

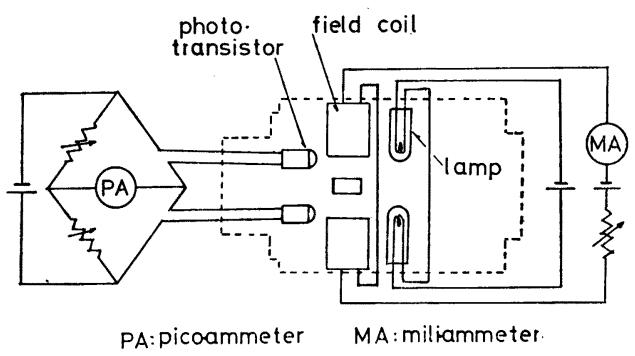

Fig. 2 Wiring diagram of the friction meter

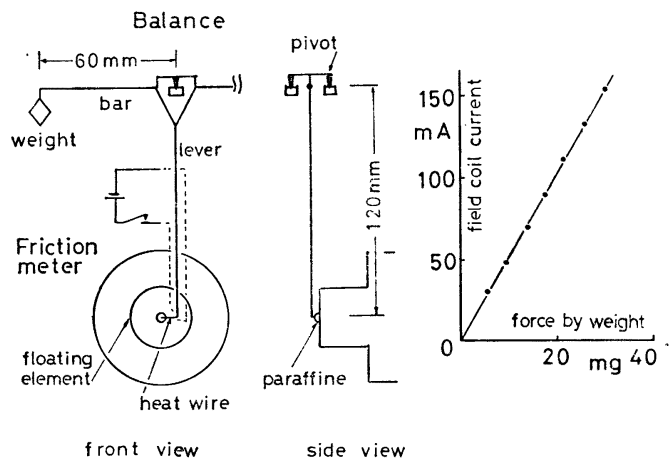

Fig. 3 Calibration balance and calibration curve 


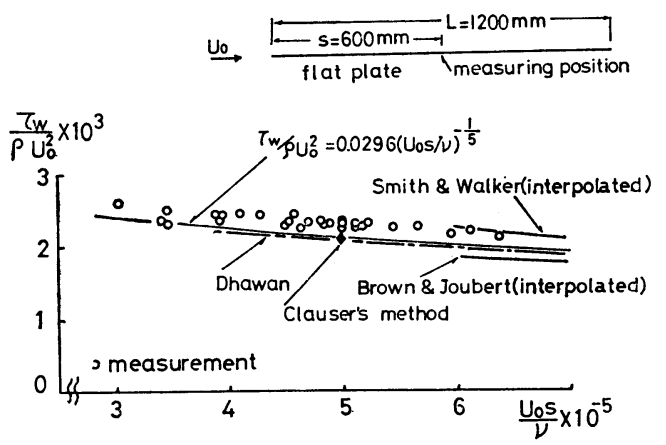

Fig. 4 Local skin friction on a flat plate

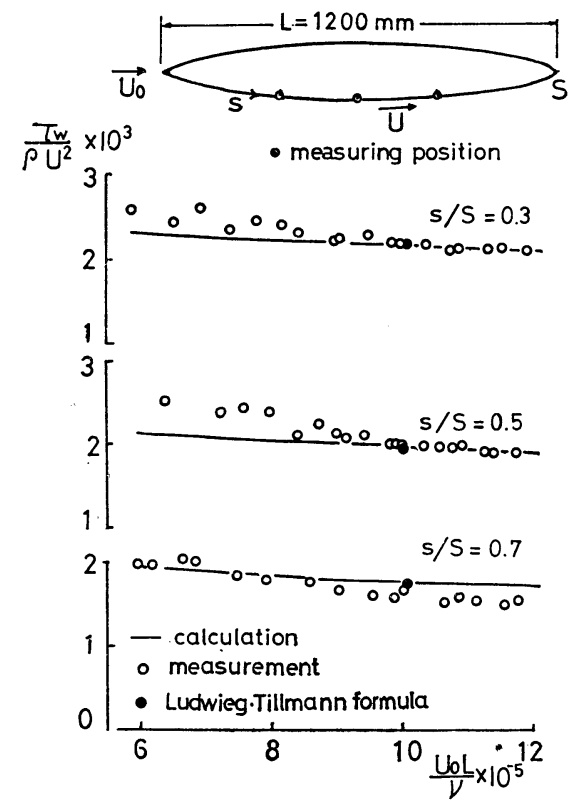

Fig. 5 Local skin friction on a twodimensional body
Table 1 Dimensions of models

\begin{tabular}{|c|c|c|c|}
\hline & Length & Thickness & Width \\
\hline Flat plate & 1200 & 2 & 400 \\
\hline & Length & $\begin{array}{l}\text { Midship } \\
\text { breadth }\end{array}$ & $\begin{array}{l}\text { Midship } \\
\text { height }\end{array}$ \\
\hline 2-Dimensjonal & 1200 & 169.8 & 400 \\
\hline $\begin{array}{c}\text { 3-Dimensional } \\
\text { body }\end{array}$ & 1200 & 191.4 & 270.8 \\
\hline
\end{tabular}

unit in $\mathrm{mm}$
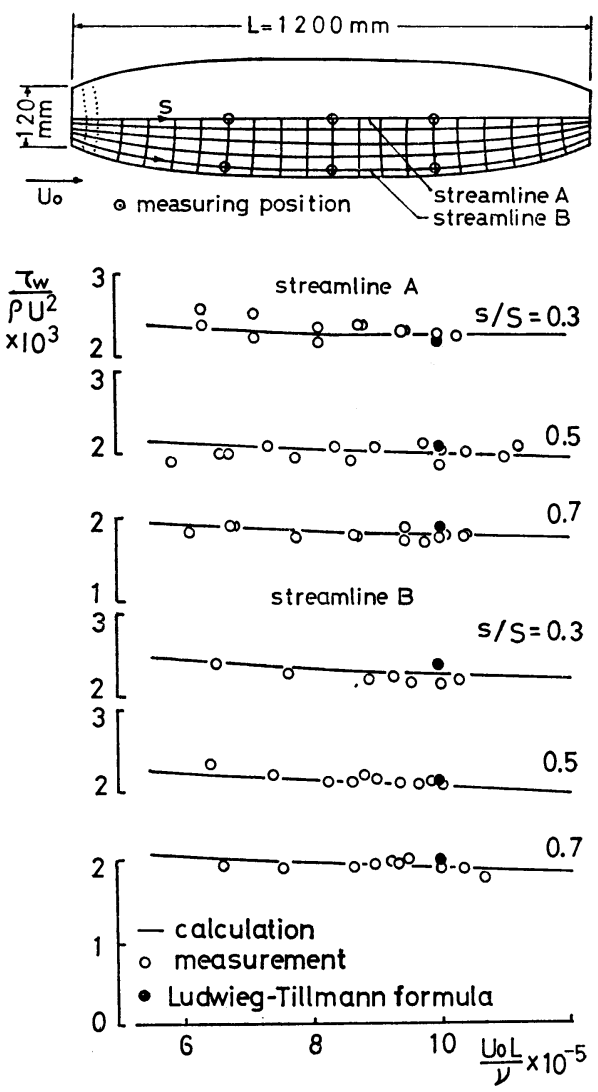

Fig. 6 Local skin friction on a threedimensional body 